\title{
Haemangioma of the Cervix Micking Cervical Endometriosis: A Case Report
}

\author{
Jaouad Kouach ${ }^{1,3}$, Youssef Benabdejlil' ${ }^{2}$, Hanane Raiteb ${ }^{2}$, Driss Moussaoui ${ }^{2,3}$, \\ Mohammed Dehayni ${ }^{2,3}$
}

${ }^{1}$ Morrocan Medical and Surgical Hospital, Zaatari Camp, Jordan

${ }^{2}$ Department of Gynecology-Obstetric, Military Hospital Mohammed V, Rabat, Morocco

${ }^{3}$ Faculty of Medicine and Pharmacy, University Mohammed V Souissi, Rabat, Morocco

\section{Email address:}

kouach_jaouad@yahoo.fr(J. Kouach), youssefbenabdejlil@gmail.com (Y. Benabdejlil), hananeraiteb@gmail.com (H. Raiteb) moussaouidriss@yahoo.fr (D. Moussaoui), Mohamedehayni@gmail.com (M. Deyahni)

\section{To cite this article:}

Jaouad Kouach, Youssef Benabdejlil, Hanane Raiteb, Driss Moussaoui, Mohammed Dehayni. Haemangioma of the Cervix Micking Cervical Endometriosis: A Case Report. Journal of Gynecology and Obstetrics. Vol. 3, No. 3, 2015, pp. 66-68. doi: 10.11648/j.jgo.20150303.15

\begin{abstract}
Haemangioma of the cervix is an extremely rare benign lesion, and only a few sporadic cases have been reported to date. In the present report we describe a case of Haemangioma of the cervix that was diagnosed in a 28 -year-old patient who consulted for post coital bleeding.
\end{abstract}

Keywords: Haemangioma, Cervix, Post Coital Bleeding

\section{Introduction}

Haemangioma of the cervix is an extremely rare benign lesion, and only a few sporadic cases have been reported [1] Haemangiomas are benign tumors that originate from endothelial cells of the blood vessels, which represent multipotent cellular elements, or from pericytes located on the outer side of the blood vessel wall. These vascular lesions may be asymptomatic or may cause abnormal vaginal bleeding which may be, rarely, life threatening. The epithelium covering these, haemangiomas is usually intact but, in exposed areas like the cervix and the vagina, traumatic ulceration of the overlying epithelium may create a lesion that tends to bleed on slight contact or trauma [2]. We report a case of cervical haemangioma, a cause of postcoital bleeding, which was managed successfully by a conservative procedure.

\section{Case History}

A 28-year-old female, Syrian, refugee in zaatari camp in
Jordan, Gravida 3, Para 2, presented to the gynecology unit of the Moroccan medical-chirurgical hospital for Syrian refugees, with complaints of low post coital bleeding since 7 month. She had no medical and family history. Her menstrual cycles had previously been regular, and of normal flow and duration. There was no history of hormonal methods of contraception and she had not undergone cervical cancer screening in the past or a history of vaginal infection. On speculum examination, her vulva and vagina appeared normal, but there was a "bluish" lesions at the front and rear lip of the cervix, with a periorificel redness, evoking first cervical endometriosis (Figure 1). No abdominal or adnexal masses were left. The rest of the physical examination was normal. The pap smear showed no abnormalities. Under spinal anesthesia and gynecological position, a resection of both lesions was made. The bleeding was contoled during surgery. Histopathological examination of the specimen was in favor of cervical heamangioma. There were no complications in the postoperative period and the patient was able to be discharged on the third postoperative day. The patient was symptom-free at 6-month follow-up. 


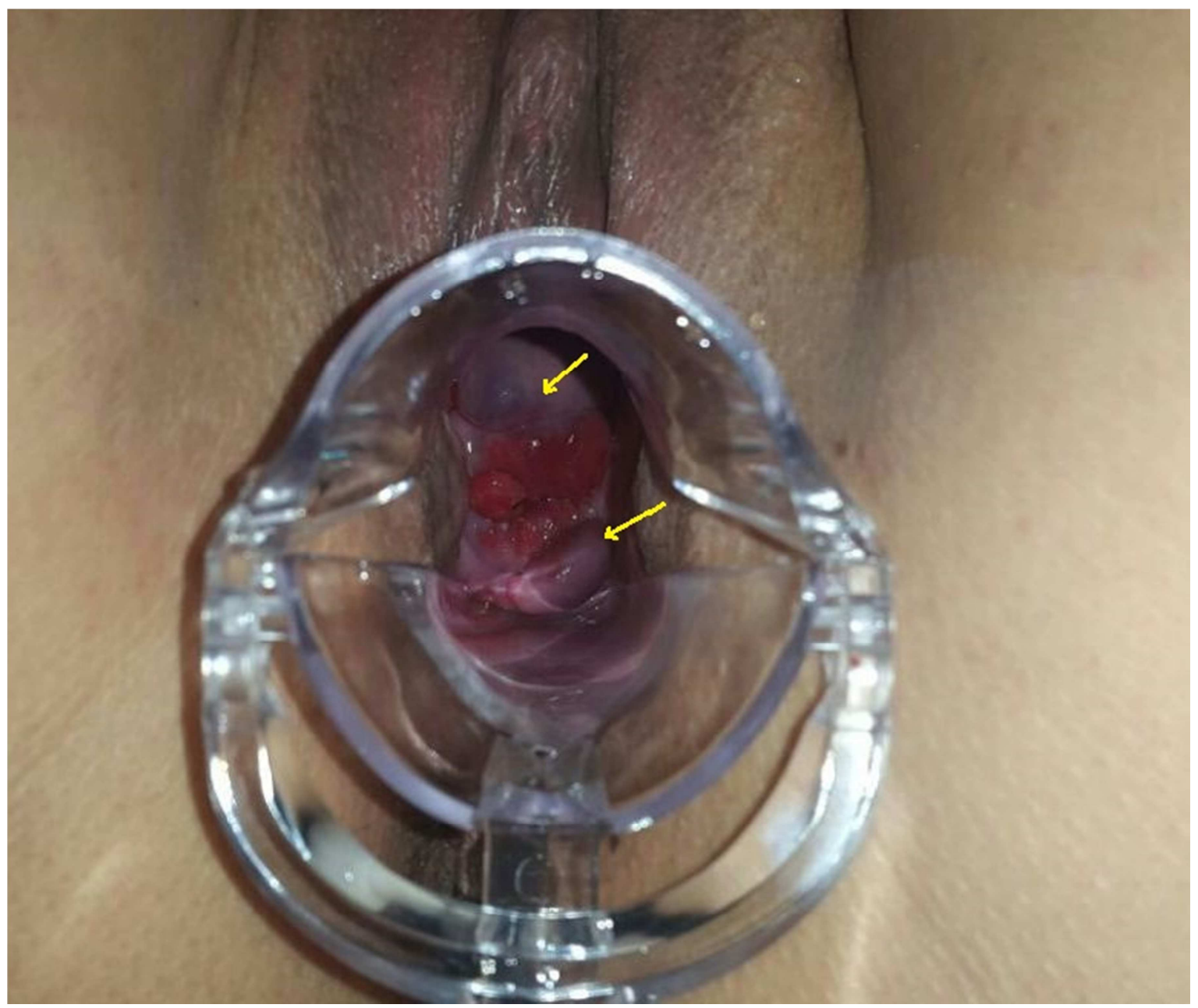

Figure 1. Speculum examination showing a "bluish" lesions at the front and rear lip of the cervix, with a periorificel redness.

\section{Discussion}

Haemangiomas are benign vascular lesions of the uterus and cervix. They may be classified as capillary or cavernous haemangiomas, angiomyomas and haemangio-endotheliomas. The first report describing a haemangioma of the cervix was by Weed in 1948 [3]. Though hemangiomas are believed to be congenital in origin, they may also develop in adults from developmental rests that have retained the potential for later proliferation [4]. The development in adults may be associated with pregnancy and oral contraceptive pill use, thereby indicating a hormonal role [2]. Bonetti et al hypothesised the possible involvement of oestrogen in the development of haemangiomas by the presence of estrogen receptors in the endothelial cells. In three cases, they found that all the tumours were immunoreactive for CD31, CD 34 and factor VIII related antigen [5]. The majority of haemangiomas are asymptomatic, because of their small size and the fact that they are discovered incidentally. Although the patients ages vary from nine to 70 years old. Most of these vascular lesions occur during the second and third decades of life and parity does not seem to play a significant role [6]. Thirty-five per cent of reported cases are associated with abnormal vaginal bleeding, like postcoital bleeding or menometrorrahgia. That was the case for our patient. These symptoms could also be due to cervicitis, particularly secondary to Chlamydia trachomatis infection. Hence, true haemangiomas must be differentiated from microvascular proliferations resulting from chronic infection [2]. Haemangiomas can also be mistakenly diagnosed as endometriosis of the cervix or squamous cell carcinoma of the cervix, particularly when this condition presents as an ulcerative lesion [5]. On topographic assessment of the cervix, port-wine, or brownish discolouration may be present, which blanches on pressure. These lesions may be small and circumscribed or diffuse, and may also extend onto the vagina and vulva [7]. Haemangiomas can also be detected incidentally during routine histopathological examination of the organ removed surgically, in the absence of a gross lesion $[7,8]$. Pregnancy may stimulate the growth or aggravate the symptoms of an existing lesion, due to a combination of various hormonal changes. The likelihood of actual blood vessel growth or angiogenesis in preexisting vascular anomalies is a possibility [7]. A case was reported where a woman presented with intractable bleeding following termination of pregnancy and the bleeding continued despite curettage and suturing, ultimately resulting in hysterectomy [9]. Padmanabhan et al reported a case of a 34-year-old woman who presented with haemangioma of the cervix and focal 
nodular hyperplasia of the liver following the use of oral contraceptive pills [10]. Of the two histological types reported in the literature, the more common is diffuse cavernous haemangioma. Cavernous haemangiomas show various-sized vessels, separated by smooth muscle and with a minimal amount of collagen-containing thrombi lined by endothelial cells. Capillary haemangiomas consist of small and clustered vascular channels lined with flat endothelial cells with intervening fibrous tissue. Haemangiomas must be differentiated from reactive granulation tissue, which would contain inflammatory cells and fibrin, and also from angiosarcomas (a malignant variant of haemangioma), which exhibit increased mitotic activity and atypia [5]. A literature search revealed that a surgical excision remains the curative treatment in most cases, and conservative therapy, such as sclerosing agents, cryotherapy, carbon dioxide laser and LEEP, may alternatively be used [5]. Transcatheter arterial embolisation, after delivery, has been reported in the treatment of rapidly growing vaginal haemangioma [11]. Although hysterectomy, as a primary mode of therapy for cases of haemangioma of the cervix presenting with vaginal bleeding, has been reported by Powell et al, most were performed because the lesion was suspected to be malignant [12].

\section{Conclusion}

Cervical haemangiomas are generally asymptomatic but can cause vaginal bleeding, and hence should be included in the differential diagnosis of patients with abnormal vaginal bleeding. Conservative procedures can be undertaken to avoid unnecessary hysterectomy.

\section{References}

[1] Ozyer S, Usunlar O, Gocmeen $\mathrm{M}$, et al. Cavernous hemangioma of the cervix a rare cause of vaginal bleeding. $\mathrm{J}$ Lower Genital Tract Disease. 2006;10(2):107-108.
[2] Ahern JK, Allen NH. Cervical hemangioma: A case report and review of literature. JReprod Med. 1978;228:228-231.

[3] Douglas JM. Hemangioma of the cervix. Obstet Gynecol. 1961;17(2):191-193.

[4] Shann SM, Dunham RJC, Wilson JD. Hemangioma of the uterine cervix. International Journal of STD and AIDS. 2004;15:486- 488 .

[5] Bonetti LR, Boselli F, Lupi M, Betelli S. Expression of estrogen receptor in hemangioma of the uterinecervix: reports of three cases and review of literature. Arch Gynecol Obstet. 2009;280:469- 472 .

[6] Kondi-Pa. ti A, Kairi-Vassilatou E, Spanidou-Carvouni H, et al. Vascular tumours of the female genital tract: a clinicopathological study of nine cases. Eur J Gynaecol Oncol.2003;24(1):48-50.

[7] Cherkis RC, Kamath CP. Haemangioma of the uterine cervix and pregnancy: a case report. J Reprod Med. 1988;33:393-395.

[8] Baxi S. Capillary haemangioma of cervix: a case report. Indian J Pathol Microbiol. 2005;48(3):373-375.

[9] Riggs J, Bertoni M, Schiavello $\mathrm{H}$, et al. Cavernous hemangioma of the cervix with intractable bleeding. A case report. J Reprod Med. 2003;48(9):741-743.

[10] Padmananbhan V, Mount SL, Eltabbakh GH. Cavernous hemangioma of the cervix in association with focal nodular hyperplasia of the liver. A case report. J Reprod Med. 2001;46(12):1067-1070.

[11] Emoto M, Tamura R, Izumi H, et al. Sonodynamic changes after trans catheter arterial embolization in avaginal haemangioma: case report. Ultrasound Obstet Gynaecol. 1997;10:66-7.

[12] Powell JL, Stephen JZ, Heather ZS. Hemangioma of the cervix managed with Nd: YAG laser. Obstet Gynecol. 1991;78(5):962- 964. 